\title{
Detecting Surface Changes from an Underground Explosion in Granite Using Unmanned Aerial System Photogrammetry
}

\author{
Emily S. Schultz-Fellenz, ${ }^{1}$ Ryan T. Coppersmith, ${ }^{2}$ Aviva J. Sussman, ${ }^{1}$ Erika M. Swanson, ${ }^{1}$ and \\ JAMES A. COOLEY ${ }^{3}$
}

\begin{abstract}
Efficient detection and high-fidelity quantification of surface changes resulting from underground activities are important national and global security efforts. In this investigation, a team performed field-based topographic characterization by gathering high-quality photographs at very low altitudes from an unmanned aerial system (UAS)-borne camera platform. The data collection occurred shortly before and after a controlled underground chemical explosion as part of the United States Department of Energy's Source Physics Experiments (SPE-5) series. The highresolution overlapping photographs were used to create 3D photogrammetric models of the site, which then served to map changes in the landscape down to 1-cm-scale. Separate models were created for two areas, herein referred to as the test table grid region and the nearfield grid region. The test table grid includes the region within $\sim 40 \mathrm{~m}$ from surface ground zero, with photographs collected at a flight altitude of $8.5 \mathrm{~m}$ above ground level (AGL). The near-field grid area covered a broader area, 90-130 m from surface ground zero, and collected at a flight altitude of $22 \mathrm{~m}$ AGL. The photographs, processed using Agisoft Photoscan ${ }^{\circledR}$ in conjunction with 125 surveyed ground control point targets, yielded a 6-mm pixelsize digital elevation model (DEM) for the test table grid region. This provided the $\leq 3 \mathrm{~cm}$ resolution in the topographic data to map in fine detail a suite of features related to the underground explosion: uplift, subsidence, surface fractures, and morphological change detection. The near-field grid region data collection resulted in a 2-cm pixel-size DEM, enabling mapping of a broader range of features related to the explosion, including: uplift and subsidence, rock fall, and slope sloughing. This study represents one of the first works to constrain, both temporally and spatially, explosion-related surface damage using a UAS photogrammetric platform; these data will help to advance the science of underground explosion detection.
\end{abstract}

1 Earth and Environmental Sciences Division, Los Alamos National Laboratory, Los Alamos, NM 87545, USA. E-mail: eschultz@lanl.gov

2 Coppersmith Consulting, Inc., 2121 N. California Blvd Ste. 290, Walnut Creek, CA 94596, USA.

3 Gresham Smith and Partners, 511 Union St, 1100 Nashville City Center, Nashville, TN 37219, USA.

\section{Introduction}

Underground explosions can produce changes that may be observed at the surface and recorded by sensors at a range of different standoff distances. The Source Physics Experiment (SPE), a series of controlled underground chemical explosive experiments conducted under the auspices of the US Department of Energy's National Nuclear Security Administration (NNSA), aims to advance the physical understanding of seismic wave propagation through geologic media (Snelson et al. 2013). An ancillary objective within SPE is to quantify and analyze permanent ground surface damage resulting from the small underground conventional chemical explosive experiments. The ground surface damage information presented here helps validate other real-time field geologic and geophysical measurements (including surface fracture mapping, downhole accelerometer instrumentation, and seismic wave analyses recorded from near-field and farfield sensors; e.g., Snelson et al. 2013; Patton 2015; Larmat et al. 2017), and provides critical input into predictive models (e.g., Larmat et al. 2015).

The formation of subtle surface features from underground activities, including explosions, depends upon the geologic environment, depth of burial, and yield. While databases exist describing surface features associated with underground nuclear explosions (e.g., Garcia 1997; Grasso 2001; Cong et al. 2007), details of the mapped features were constrained by the data capture method and the target of the mapping program. Previous studies have described morphological changes, such as fracturing and shifting of underground infrastructure, resulting from 
underground conventional explosions (e.g., Cattermole and Hansen 1962; Phang et al. 1983; Yu et al. 2014; Chowdhury and Wilt 2015), but have not described detailed changes at the ground surface or explored changes at the $\mathrm{cm}$ - to sub-cm scale. Similarly, while airborne and satellite remotely sensed methods have been employed to detect morphological changes and dynamic geological processes such as landslides, flooding, and coastal change (e.g., Gutierrez et al. 2001; Glenn et al. 2006; LePrince et al. 2008; Niethammer et al. 2010; Scaioni et al. 2014; Pelletier and Orem 2014; Warrick et al. 2016), the meter-scale data resolution range may overlook important, but smaller features. The acquisition, analysis, and interpretation of $\mathrm{cm}$-scale change detection data from ground-based and ground-proximal methods provide important constraints for, and validation of, the possible range of scales for relevant features, thereby allowing us to better constrain the mechanisms that govern the damage patterns expressed at the ground surface.

Recent studies have advanced the use of photogrammetry into the field of geologic mapping and landform change detection (e.g., James and Varley 2012; Fonstad et al. 2013; Hugenholtz et al. 2013; Tuffen et al. 2013; Micheletti et al. 2015; Piras et al. 2017). To apply photogrammetry to morphological change detection studies in national and global security applications, such as the detection of smaller and/or deeper events, data collections need to be nimble, rapid, non-invasive, and non-destructive while providing high-resolution data. When signatures are subtle, data captured from greater standoff distances may not possess the resolution needed to detect changes. Furthermore, the methods required to capture ground-based lidar and traditional mapping data may destroy signatures of significance. Lowaltitude $(<100 \mathrm{~m}$ above ground level) unmanned aerial systems (UAS) with photogrammetric assets meet these needs and position this technology to grow further into geologic signature and change detection for national and global security application spaces. Here we present data and methods from UAS photogrammetry collections, executed with a dense grid of ground control points, before and after an underground conventional explosive experiment. We demonstrate that small-yield underground explosions in granite elicit a detectable surface expression of damage. We validate the proof-of-concept for applicability of a UAS-based Structure-from-Motion (SfM) workflow for fine-scale surface change-detection studies and test the operation's ability to produce results comparable to terrestrial lidar. We compare the observed changes with the regional geologic setting and discuss the benefits of integrating imagery and topographic data in the interpretation of signatures from underground activities.

\section{Setting}

The field area is located within the Nevada National Security Site (NNSS), formerly the Nevada Test Site (Fig. 1). The data collection site is a $250 \mathrm{~m} \times 200 \mathrm{~m}$ region broadly centered on the SPE emplacement borehole (Fig. 2) and is underlain by the Climax Stock. The Climax Stock is a Cretaceousaged, fine- to medium-grained coarsely porphyritic quartz monzonite, comprised largely of quartz, potassium feldspar, plagioclase, and minor biotite (Orkild et al. 1983). Syn- and post-emplacement hydrothermal alteration of the Climax Stock produced moderate argillic alteration of plagioclase throughout the intrusion. The Boundary Fault, a basin-bounding normal fault active in the Quaternary, separates the monzonite stock from nearby Yucca Flat. This fault strikes north- to northeast and has accommodated between $\sim 250 \mathrm{~m}$ (Orkild et al. 1983) and $600 \mathrm{~m}$ (Maldonado 1977) of throw. Dominant joint sets are N64W, 90; N32W, 22 NE; and N35E, 90 (Houser and Poole 1960).

The field site (Fig. 2) consists of a flat-graded region serving as the test table, a bermed sump southeast of the test table (known as the "muck pit") to trap and hold drilling fluids and runoff, an $\sim 7 \mathrm{~m}$ high quartz monzonite rock outcrop west of the southwesterly corner of the test table, and a broad region of native terrain outside of the margins of the test table that includes undulating topography, a small east-west oriented drainage, and scrubland vegetation. This study captured data in association with the fifth SPE test in the series (hereafter referred to as SPE-5). SPE-5 involved the detonation of chemical high explosives within a cylindrical canister 


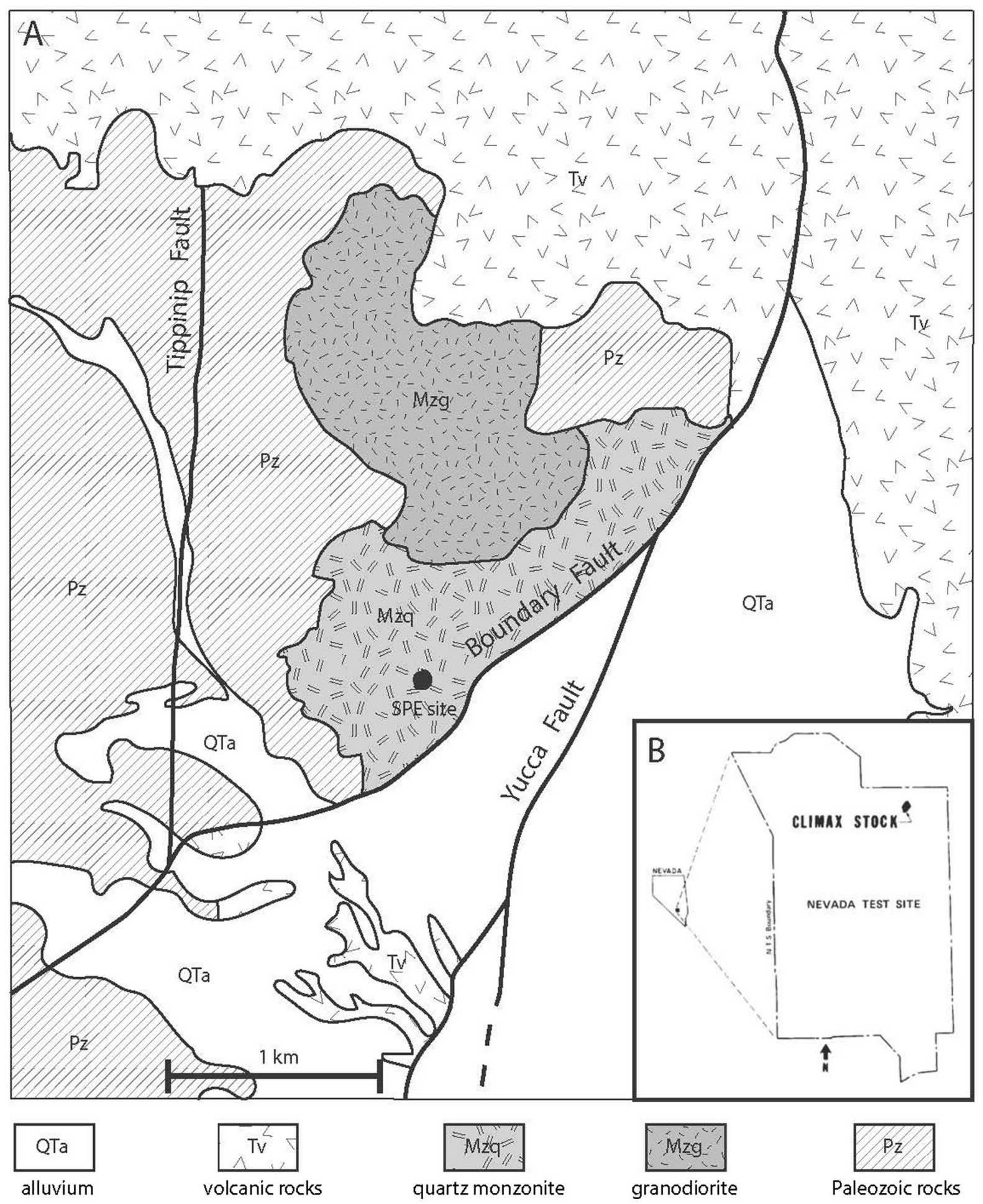

emplaced in a 91.4-cm diameter borehole with a centroid charge depth of $76.5 \mathrm{~m}$. Above the subsurface explosive canister, the emplacement hole was backfilled with stemming materials, including gravel and poured grout. The underground experiment, a casting of PBXN-114 with a 5035-kg trinitrotoluene 
Figure 1

Location of the SPE site. a Simplified geologic map of the Climax Stock quartz monzonite, showing exposed geologic units and regional structures; note in particular the orientation of the Boundary fault. Geologic unit prefixes indicate age; $Q$ Quaternary, $T$ Tertiary, $M$ Mesozoic, $P$ Paleozoic. b Inset showing location of the Climax stock with respect to the NNSS and the state of Nevada. Modified from Houser and Poole (1961)

(TNT) equivalent, was successfully executed at 13:49.00 local time on 26 April 2016. The experiment occurred in the same borehole as four previous experiments in the SPE series and, therefore, exploited a pre-damaged geologic media, although the pre-existing geologic damage existed predominantly at shallower depths.

\section{Methods}

Past surface change detection studies for the SPE program used conventional terrestrial lidar scanning solutions to produce datasets with spatial vertical surface change $(\Delta z)$ resolution on the order of $2.8 \mathrm{~cm}$ locally (Fig. 3). However, inefficiencies in the execution of the terrestrial lidar studies at the site and potential ground disturbance caused by the intrusive nature of the collection methodology led us to employ a different technology solution to document changes in surface topography and allowed us to better understand how the ground surface responds to subsurface deformation from an explosion in a lessinvasive and more rapid manner. Field methods for pre-experiment and post-experiment data capture involved SfM techniques from high-quality photographs collected by a commercial off-the-shelf DJI Inspire 1 quadcopter UAS equipped with a standard, commercial camera. This system operated at altitudes between 8.5 and $22 \mathrm{~m}$ above ground level (AGL). The resulting data products include digital elevation models (DEMs) derived from 2D imagery.

\subsection{Structure-From-Motion}

With a paramount need to acquire low-cost, timeefficient, high-resolution topographic data, this study utilized SfM technology. SfM is a useful range viewing technique that refers to the process of estimating 3D geometries from 2D images. This methodology has become increasingly popular in a wide range of geologic and geomorphic investigations and standoff distances in the past half-decade (e.g., Westoby et al. 2012; Niethammer et al. 2010; Johnson et al. 2014; Bemis et al. 2014; Micheletti et al. 2015; Nouwakpo et al. 2015; Reshetyuk and Martensson 2016; Carrivick et al. 2016; Piras et al. 2017) and provides valuable data to link with other geological and geophysical techniques. The Agisoft Photoscan ${ }^{\circledR}$ software package is a powerful SfM tool that uses photogrammetric algorithms to calculate distances between points in overlapping photos to create high-resolution 3D models from 2D images. The resolution of the final 3D model is dependent on the resolution of the $2 \mathrm{D}$ photographs and the ratio of frontal and side overlap with neighboring photos. The model can be optimized and georeferenced with ground control points (GCPs) with positions measured by high-precision real-time kinematic (RTK) GPS.

This study's objective was to acquire detailed 3D topographic information from a site in a rapid, minimally invasive, and evenly distributed fashion across uneven terrain to determine what surface changes result from a small-yield explosion in granitic rock. A UAS-borne photogrammetric system provided an optimal data collection platform to meet this objective. This campaign largely follows the principles of Westoby et al. (2012) and the field and analytical methodology outlined by Bemis et al. (2014) for SfM photogrammetric data of geologic field targets. SfM approaches have successfully utilized oblique imagery from terrestrial and airborne manned platforms (James and Robson 2012; Tuffen et al. 2013; Molinari et al. 2014). However, due to the relatively low topography and low vegetation cover, this campaign prioritized UAS photo collection at a consistent altitude above ground level with a nadir camera angle. Further, this study leveraged the capability of the DJI Inspire 1 to fly slowly $(\sim 1 \mathrm{~m} / \mathrm{s})$ at our desired $8.5 \mathrm{~m} \mathrm{AGL}$ low ceiling to capture the highest resolution images possible. 


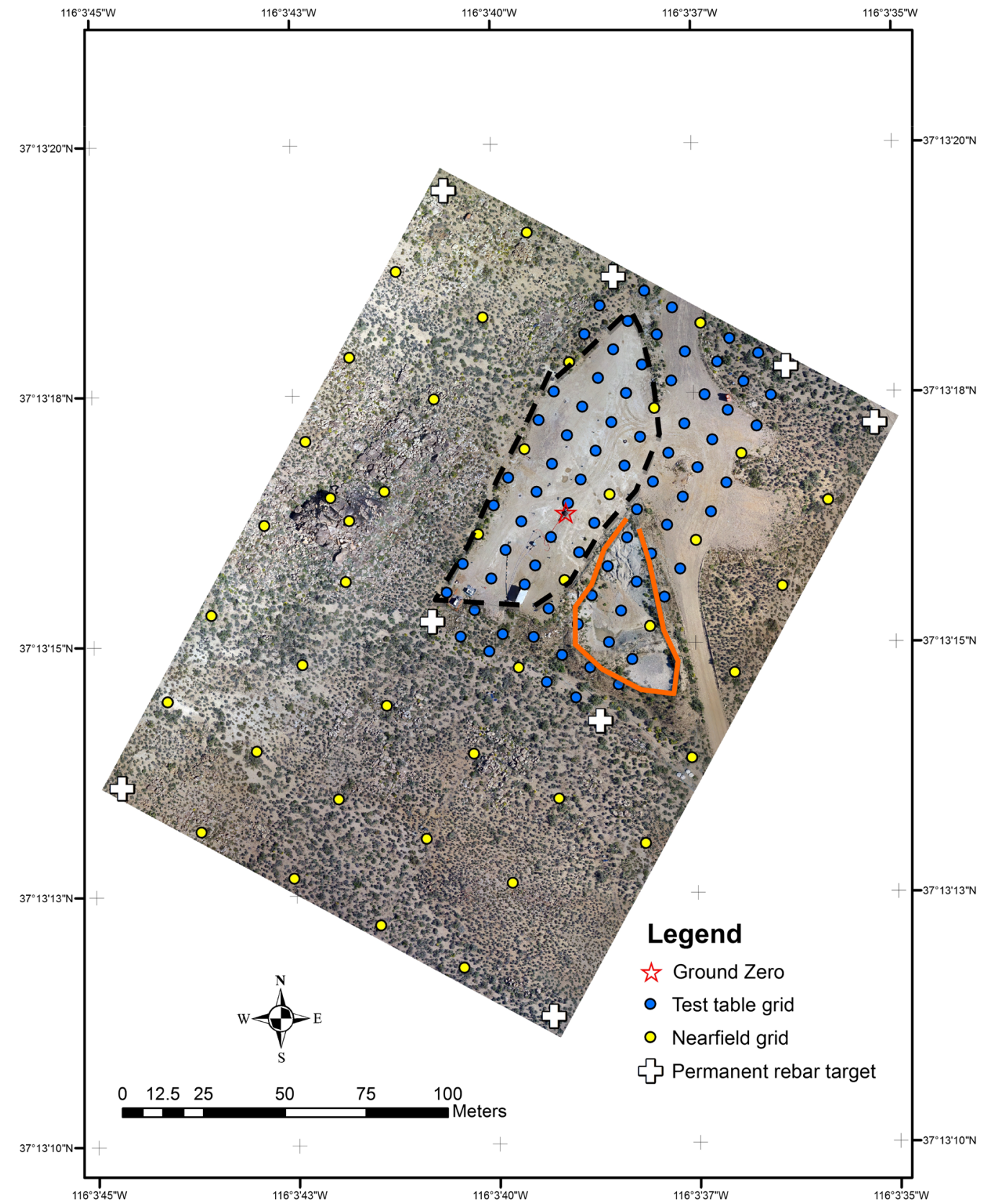

Figure 2

Study area with locations of test table grid (blue dots), near-field grid (yellow dots), and permanent (white crosses) ground control point targets. SPE-5 emplacement hole at surface ground zero shown as red star. Boundaries of test table (black dashed line) and muck pit (solid orange line) shown

\subsection{GCP Grid Design and Installation}

While recent studies have explored direct georeferencing of UAS photogrammetry data (e.g., Jozkow and Toth 2014; Carbonneau and Dietrich 2016), this study required that final data products be accurately georeferenced for high-resolution change detection. This required a careful and sufficiently dense grid of surveyed ground control points (GCPs) to translate 
SPE-2

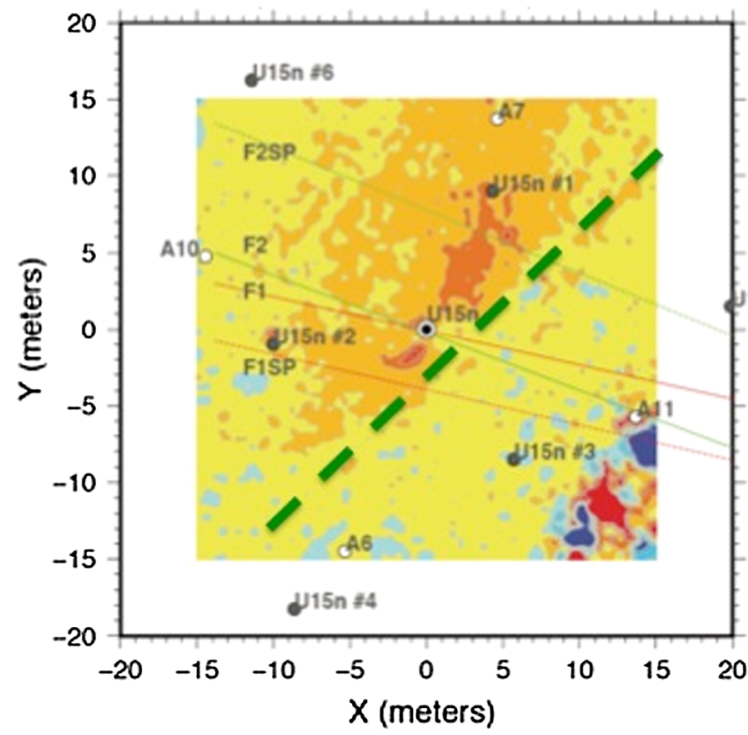

SPE-3

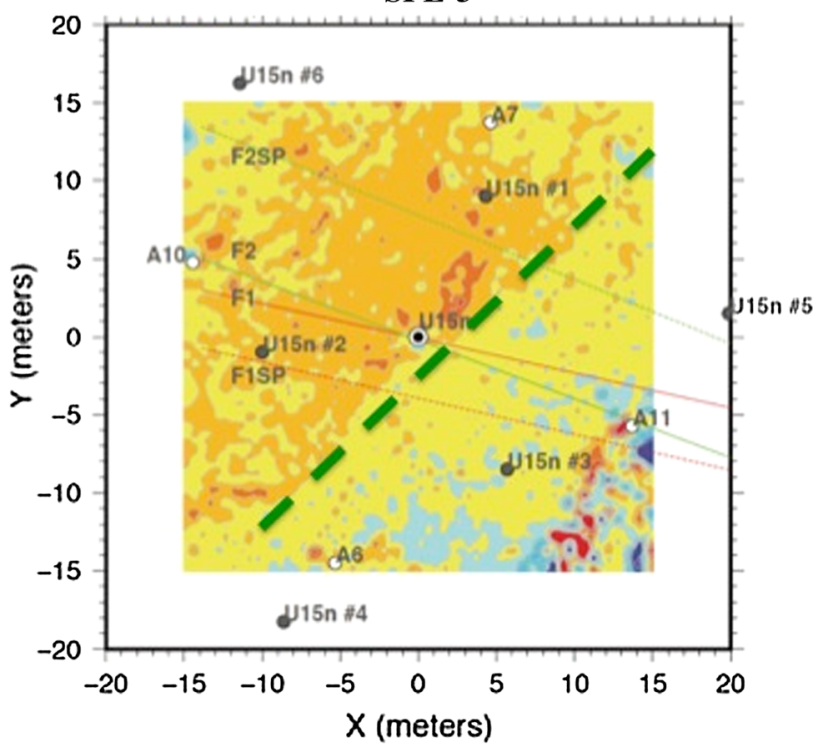

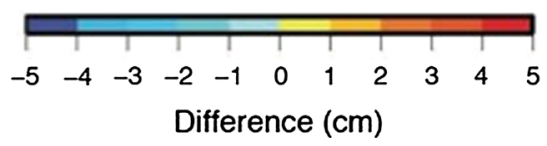

Figure 3

Surface vertical change detection $(\Delta z)$ maps from analyses of pre- and post-test terrestrial lidar data for previous SPE tests (SPE-2, left; SPE-3, right). Coordinate 0,0 is the SPE test emplacement hole (labeled U15n). Green dashed line represents a geologic feature along which surface $\Delta z$ appears to align. Modified from Schultz-Fellenz et al. (2013)

the photogrammetry data into an absolute spatial reference frame and obtain the highest quality and accuracy geospatial output. The GCPs served as passive pilot guidance during airborne operations, provided the reference framework to collect photographs with sufficient overlap percentage, and allowed for 3D model optimization. The density of the GCP grid (Fig. 2) sought to eliminate systematic errors in models generated from photographic datasets using images captured orthogonal to the target surface of interest (e.g., James and Robson 2014).

Within the field site, a Topcon HiPer V base and rover unit utilized real-time kinematic (RTK) differential GPS procedures to stakeout approximate locations for 126 temporary and permanent GCPs. The baseline horizontal accuracy of the HiPer V GPS is $10 \mathrm{~mm}+1 \mathrm{ppm}$, and vertical accuracy is $15 \mathrm{~mm}+1 \mathrm{ppm}$. GPS site control was established using the Online Positioning User Service (OPUS) available from the National Geodetic Survey. Overall control of the SPE site was established based on three independent OPUS solutions performed on three separate days. GCPs were installed at $10 \mathrm{~m}$ spacing for the test table grid area, and $30 \mathrm{~m}$ spacing for the nearfield grid area. The temporary GCPs were laminated, brightly-colored $21.6 \mathrm{~cm} \times 27.9 \mathrm{~cm}$ paper targets labeled with a unique identifier (a letter and a number), each secured to the ground by $7.6 \mathrm{~cm}$ long household nails with a center nail acting as the survey marker (Fig. 4a). Given that the field site intended to host future experiments, it was prescient to install several permanent ground control monuments well away from the region of anticipated damage to ensure that future ground control can reference undisturbed monuments (Fig. 4b). These permanent targets consisted of $1 \mathrm{~m}$ square black-andwhite striped plastic fiducial sheets, secured to the ground with a combination of rebar, $10.16 \mathrm{~cm}$ nails with $5.08 \mathrm{~cm}$ washers, and rocks. The team surveyed the centerpoint of each GCP for absolute spatial control, using the same Topcon RTK differential 


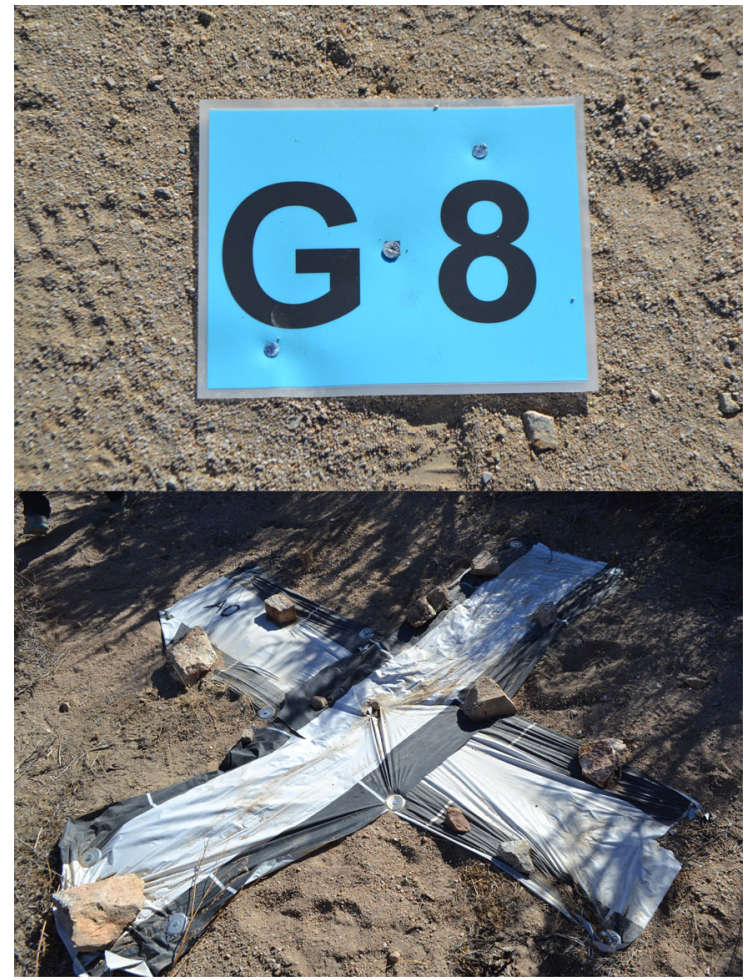

Figure 4

Examples of the temporary (top) and permanent (bottom) GCP markers in the study area

GPS, to acquire high-fidelity position information for approximately $30 \mathrm{~s}$ (30 epochs) per temporary target and 3 min (180 epochs) per permanent target, with redundant checks on all permanent targets. Targets were surveyed prior to airborne operations during the pre-experiment collection and resurveyed following airborne operations for the post-experiment collection.

\subsection{UAS Platform and Airborne Operations}

This campaign utilized a DJI Inspire I dualcontrol quadcopter UAS, operated with master (flight) and slave (camera) controls. For the test table grid region, the UAS operated at an 8.5-m AGL flight ceiling. For the near-field grid region, the UAS operated at a 22-m AGL flight ceiling. From these positions, the UAS collected predominantly nadir still photography using its standard onboard X3 FC350 12 megapixel camera. The field collection area also served as the launch, landing, and recharging point for the UAS. The nominal flight time for a single battery for the UAS was approximately $17 \mathrm{~min}$. Due to external constraints on deployment time, the team required no fewer than eight spare batteries, with continuous recharging capability, to ensure multiple hours of operation and data collection.

After completion of ground checks and sensor calibration, the team flew the UAS in a planned flight pattern to obtain appropriate photo overlap. For optimal data quality, the team required $>65 \%$ side photo overlap and $>80 \%$ frontal photo overlap across the entirety of the field area. This was accomplished using the GCPs as reference and a flight operations workflow that captured the same GCP in multiple frames (Fig. 5). Further, calibration of the flight altitudes to the GCP spacing achieved the desired photo framing. Using the slave controller for image capture operations, the team could view and capture each GCP in no fewer than nine separate positions within individual images (e.g., within single frames, each GCP was captured in the top left/center/right, center left/center/right, and the bottom left/center/ right), thus yielding the required image overlap. The high-resolution photographs collected at high overlap and a low flight ceiling created a seamless and spatially robust point cloud dataset. The establishment of flight boundaries set 10-20 m beyond the study area ensured full coverage and avoided the zone of boundary artifacts that can occur during photogrammetric processing. Due to the variation of vegetation thickness and topographic in the study area, the collection coordinated the timing of certain flight paths with favorable lighting conditions whenever possible: data collection over highly vegetated and high relief locations occurred closer to mid-day to reduce shadowing, whereas the flatter, less vegetated locations were flown during the lower light angle hours. Since the SPE-5 test date had been set for 26 April 2016 and the test was densely instrumented with other scientific and technical diagnostics, a fixed data collection schedule was developed by the SPE campaign leadership. For UAS photogrammetry, the pre-test data collection occurred across eight daylight flight hours on 19 and 20 April 2016 in clear, cloudless conditions. The explosion was executed on schedule on 26 April 2016. The post-test data collection took place across six daylight 
A

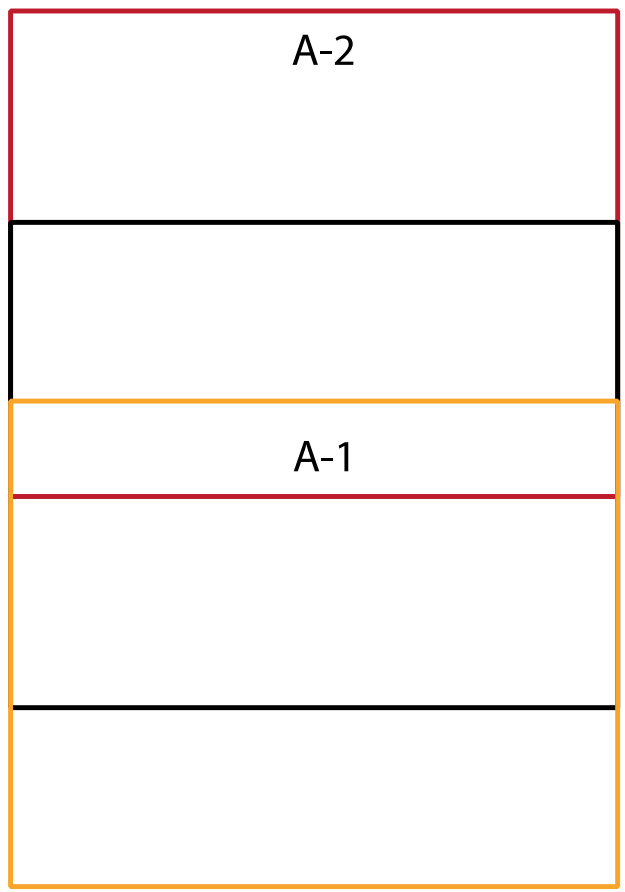

B

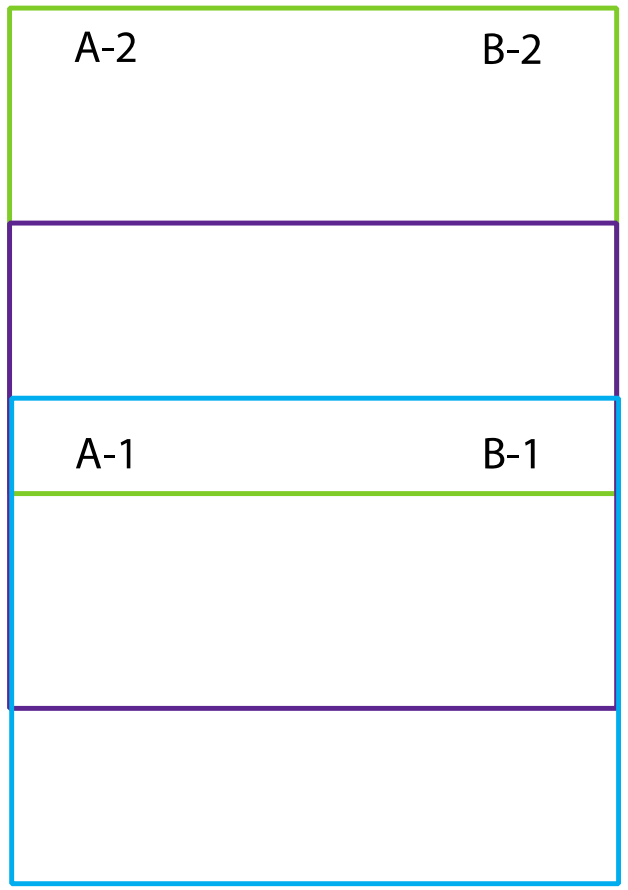

Figure 5

Schematic showing the positioning of GCPs in image frames to secure the required amount of photo overlap for 3D model generation. Three photos were taken at each GCP target. Left panel shows photo frame (square) centered on GCP target A1 in the top, center, and bottom of the camera frame. Right panel shows photo centered between the targets providing sufficient side overlap

flight hours on 27 and 28 April 2016 under evenly cloudy skies.

After the first day of each data collection, all captured images underwent review to confirm sufficient photo overlap and the focus of the imagery. Areas with insufficient overlap or poor quality photos were reflown on the second day.

\subsection{Geospatial Data Processing and DEM Development}

Aerial imagery data, in conjunction with surveyed GCPs and Agisoft Photoscan ${ }^{\circledR}$, served as the basis for developing the $3 \mathrm{D}$ models. After removing poorly focused, blurry, or lower-quality photos, between 1060 and 1620 photographs per model were imported into Agisoft Photoscan ${ }^{\circledR}$ for processing and model generation (Table 1).

The software first aligns the photographs based on finding 'like' points in the overlapping portions of the images. Then, manual assignment of survey points within the photographs was performed for every location where the GCPs are visible.

The more accurate locations of the surveyed GCP targets optimize the locations of the aligned photos, both with respect to all other photos in the model and in an absolute spatial reference frame. After location optimization, the dense 3D point cloud is generatedthe most computationally demanding part of the analysis. Figure 6 summarizes the steps of this process.

\section{Results}

Results of the photo data collection and subsequent DEM models are summarized in Table 1 and discussed below. The models relied heavily on the survey control that provided $1 \mathrm{~cm}+1 \mathrm{ppm}$ horizontal and $1.5 \mathrm{~cm}+1 \mathrm{ppm}$ vertical resolution at 
Table 1

Parameters and model information for the four DEMs generated in this study

\begin{tabular}{|c|c|c|c|c|c|c|c|c|c|c|}
\hline \multirow[t]{2}{*}{ Model } & \multicolumn{5}{|c|}{ Camera locations and image overlap } & \multicolumn{3}{|c|}{ Model optimization } & \multicolumn{2}{|c|}{$\begin{array}{l}\text { Final point cloud and } \\
\text { DEM results }\end{array}$} \\
\hline & $\begin{array}{l}\text { Number } \\
\text { of } \\
\text { images }\end{array}$ & $\begin{array}{l}\text { Aligned } \\
\text { photos }\end{array}$ & $\begin{array}{l}\text { Flying } \\
\text { altitude } \\
(\mathrm{m})\end{array}$ & $\begin{array}{l}\text { Coverage } \\
\text { area } \\
\left(\mathrm{km}^{2}\right)\end{array}$ & $\begin{array}{l}\text { Ground } \\
\text { resolution } \\
(\mathrm{mm} / \mathrm{pix})\end{array}$ & $\begin{array}{l}\text { GCP } \\
\text { targets }\end{array}$ & $\begin{array}{l}\text { Total error- } \\
\text { GCP camera } \\
\text { optimization }(\mathrm{m})\end{array}$ & $\begin{array}{l}\text { Reprojection } \\
\text { error based on } \\
\text { GCPs (pix) }\end{array}$ & Point count & $\begin{array}{l}\text { DEM } \\
\text { resolution } \\
(\mathrm{cm} / \mathrm{pix})\end{array}$ \\
\hline $\begin{array}{l}\text { Preshot test } \\
\text { table grid }\end{array}$ & 1241 & 1240 & 8.24 & 0.0181 & 3.07 & 92 & 0.0066 & 1.95 & $480,768,917$ & 0.0614 \\
\hline $\begin{array}{c}\text { Postshot test } \\
\text { table grid }\end{array}$ & 1504 & 1504 & 9.23 & 0.0141 & 3.44 & 65 & 0.0069 & 2.1 & $416,011,453$ & 0.0687 \\
\hline $\begin{array}{l}\text { Preshot } \\
\text { near-field } \\
\text { grid }\end{array}$ & 1060 & 1060 & 23.4 & 0.0521 & 8.74 & 53 & 0.0147 & 2.04 & $281,877,253$ & 1.75 \\
\hline $\begin{array}{l}\text { Postshot } \\
\text { near-field } \\
\text { grid }\end{array}$ & 1623 & 1623 & 21.5 & 0.0548 & 8.1 & 45 & 0.0154 & 2.02 & $349,781,020$ & 1.62 \\
\hline
\end{tabular}

GCP locations. The results of the survey portion of the study included the high-resolution position capture of $126 \mathrm{GCP}$ targets for the pre-test survey. After photo collection for the pre-test effort, 38 GCP targets moved from non-test related occurrences (e.g., weather). Therefore, the post-shot survey yielded 88 GCP locations.

\subsection{Photo Overlap and Alignment Analysis}

Table 1 also presents a summary of the number of photos analyzed and aligned in each model. The field campaign yielded excellent photo coverage, with photo overlap typically exceeding nine photos per point throughout each model (Fig. 6). These values indicate that the flight workflow shown in Fig. 5 was executed correctly with each GCP target captured in at least nine photos. This resulted in very high ground resolution, based on image quality rather than spatial control, and also generated orthoimagery as a data product.

\subsection{GCP Input and Dense Point Cloud Construction}

Introduction of absolute positions of GCPs to the models occurred after the photo alignment stage, through manual placement of GCP markers on the center nail as seen in the GCP target indicated in Fig. 4. This action took place approximately 800 times for each model, given the number of GCP targets and the coverage of at least 9 photos per target. (At the time of publication, no automated process to perform this step is known.) As described earlier, even though fewer GCP targets were available for use in the post-test model, sufficient special GCP coverage existed in the remaining 88 preserved post-test GCP network to ensure a low re-projection error (Table 1). After GCP placement, the model was optimized based on these locations. The total error based on this optimization is provided in Table 1. Sub-centimeter $(\sim 6.5 \mathrm{~mm})$ error was achieved for the test table grid locations, whereas $\sim 1.7 \mathrm{~cm}$ total error was achieved for near-field grid locations.

During dense point cloud generation, the "High" resolution and "Aggressive" filtering settings in Agisoft Photoscan ${ }^{\circledR}$ were used. The total points in the four models presented in Table 1 show consistent coverage for the test table grid and near-field grid locations across the pre- and post-shot models. The point clouds registered no data gaps due to the densely overlapping photo coverage and extension of flight paths $10-20 \mathrm{~m}$ beyond the desired data capture region.

The GCP network was also comparatively examined from pre-test to post-test, to assess whether the underground explosion resulted in any lateral translation ( $\Delta x$ and/or $\Delta y)$ of portions of the area. 

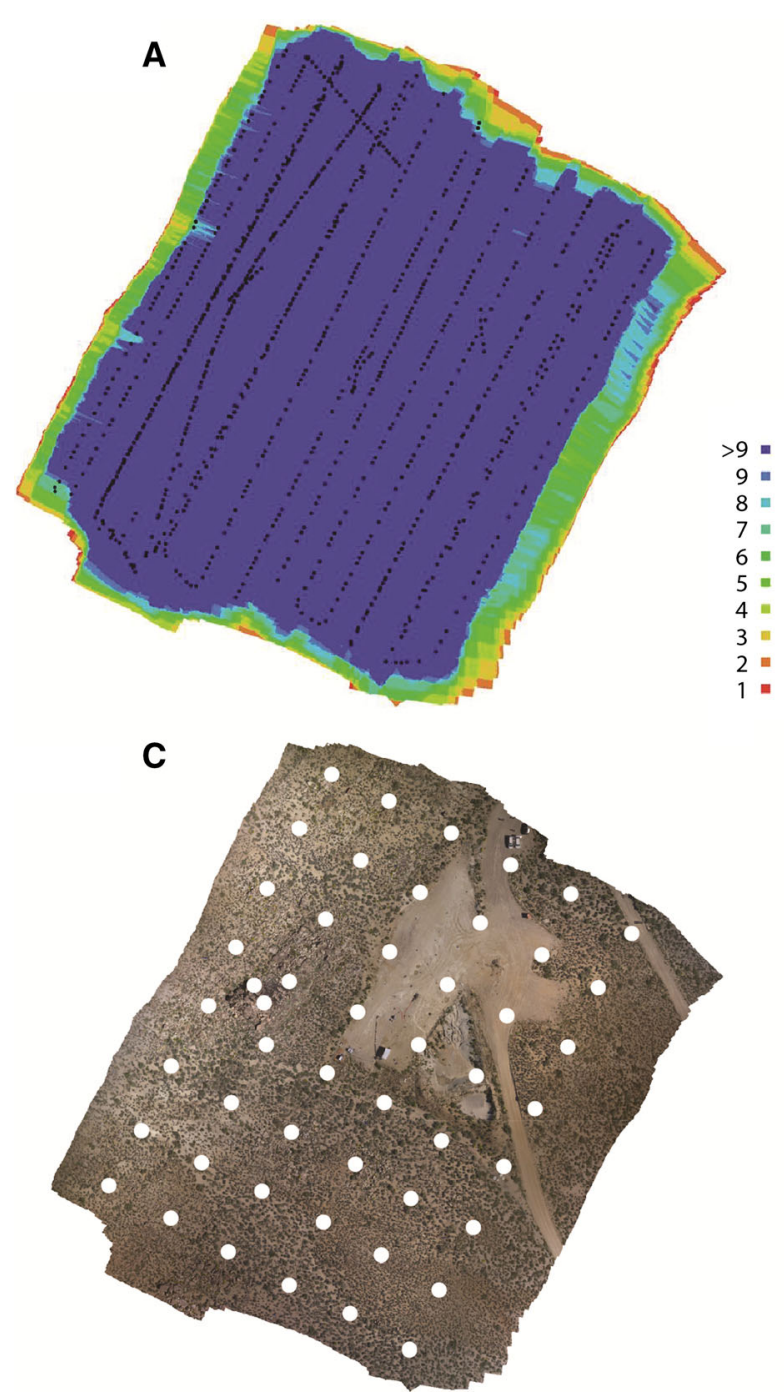
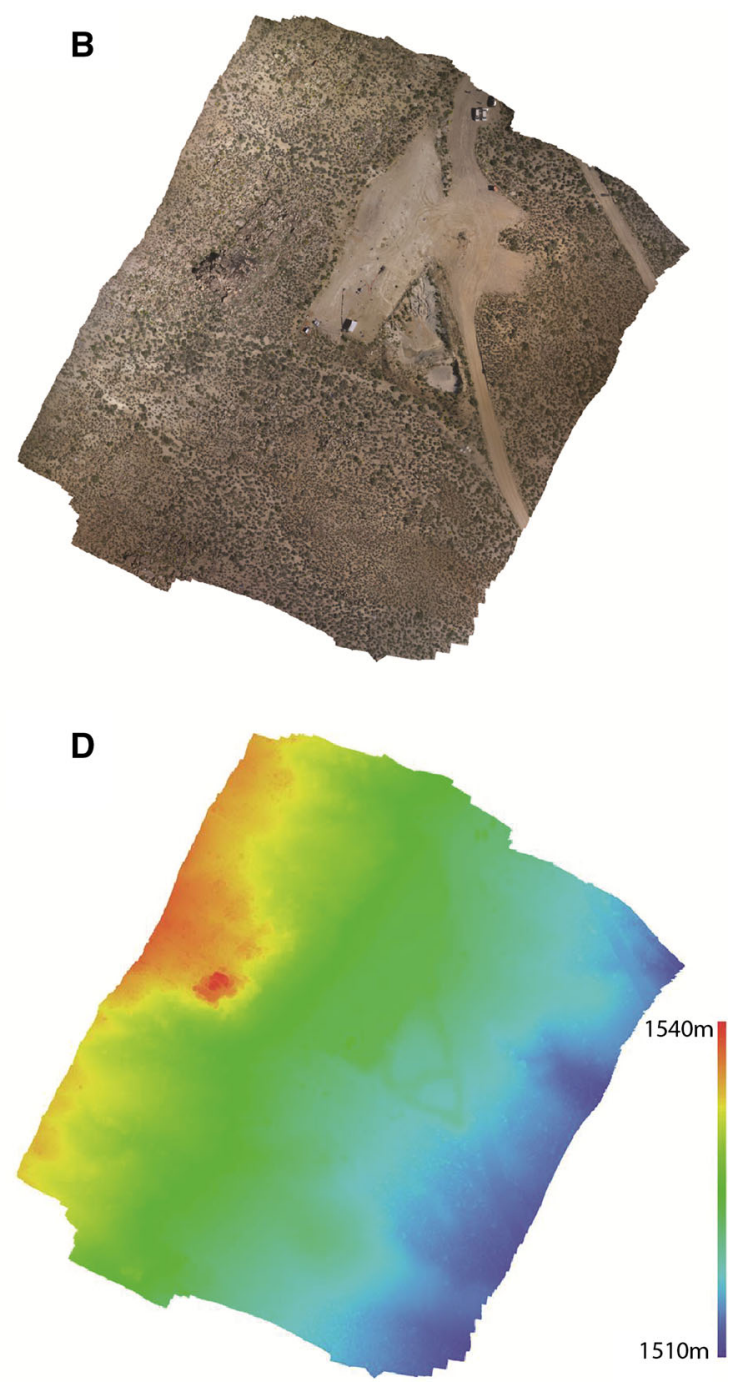

Figure 6

Simplified steps of the Agisoft Photoscan ${ }^{\circledR}$ workflow including: a photo overlap analysis; color legend indicates number of photos available at a given location, $\mathbf{b}$ point cloud creation, $\mathbf{c}$ georectification from GCPs, and $\mathbf{d}$ DEM construction

\subsection{Hillshade DEMs}

Following georectification, the dense point cloud was processed into a DEM. As indicated in Table 1, the resolution of the test table grid area DEMs was approximately $6.5 \mathrm{~mm}$ and nearfield grid area were approximately $1.7 \mathrm{~cm}$. Figure 7 presents hillshade maps derived from the DEMs for the test table grid region pre- and post-shot models. These models generated details sufficient to map fine-scale features on and near the test table (Fig. 8). Some of the features visible in the dataset include small $(1-2 \mathrm{~cm}$ diameter) cobbles, GCP paper targets, cables, rills, tire tracks, sandbags, and footprints. Additionally, more spatially extensive features such as zones of uplift and subsidence at various locations around the test table, large (40-50 cm diameter) boulders, rock fractures, and surface grading or filling are detectable. The DEMs resulting from the test table grid region contain minimal noise, since the construction of the DEM relies largely on the dense GCP network. 

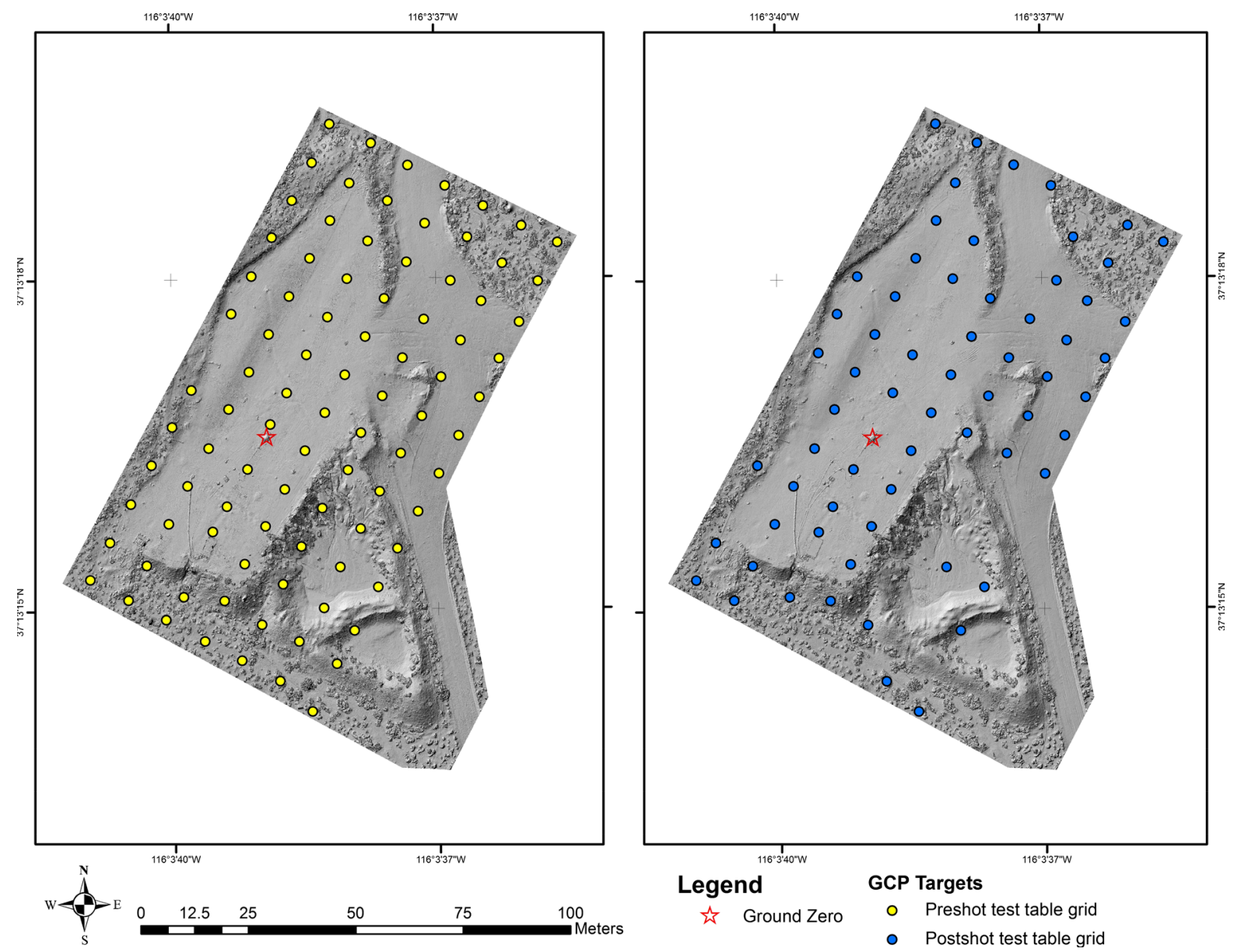

Figure 7

Hillshade maps derived from $6.5 \mathrm{~mm}$ DEMs from the test table grid region. The left panel is the pre-test model and the right panel is the posttest model. Ninety-two GCP targets (yellow dots) were surveyed in the pre-test model, whereas 65 GCP targets (blue dots) were surveyed in the post-test model

Areas of the near-field grid DEM off the graded test table, however, do show noise, likely resulting from vegetation in these areas. This noise is ameliorated by the resurvey of GCPs in the near-field grid postexperiment, indicating no vertical change in the position of GCPs.

A major feature in the near-field grid region is a granite outcrop (Fig. 9). Individual boulders, fractures, and GCP targets were mapped in this outcrop for change analysis. A raster differencing of the pretest from the post-test DEMs provides both quantification and visualization of the spatial extent of vertical surface deformation $(\Delta \mathrm{z})$ resulting from the SPE-5 test (Fig. 10).

\subsection{Data Resolution}

Within the near-field grid area, a total of 1060 overlapping photos were collected at an average $22 \mathrm{~m}$ AGL flight ceiling. Processing these photos in Agisoft led to the generation of a dense point cloud (5410 points $/ \mathrm{m}^{2}$ ) and a $1.7-\mathrm{cm}$ hillshade DEM (Fig. 8). Data of this resolution permit the accurate mapping of discrete surface fractures (including strike and dip analyses) and $\Delta z$ and volumetric difference analyses (when used as a change-detection tool).

Data collection in the test table grid region yielded 1241 overlapping photos collected at an average $9 \mathrm{~m}$ AGL flight ceiling. The Agisoft 

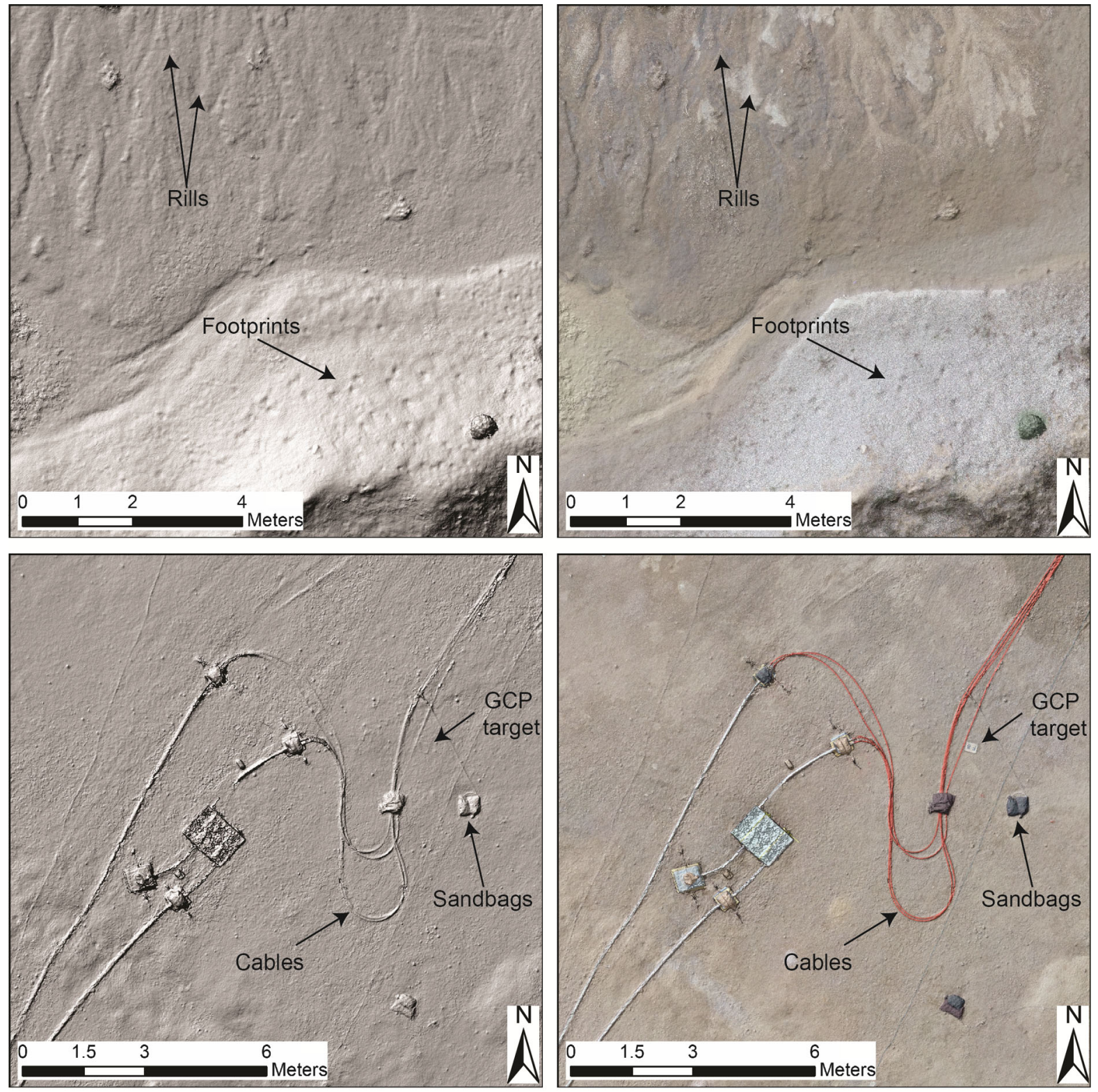

Figure 8

Examples of high-resolution hillshade DEMs (left panels) plus draped orthoimagery (right panels; with 50\% DEM transparency) from the test table grid post-shot model. Upper images footprints in the lower half of the image on the slope of the muck pit, and localized rills with centimeter-scale incision. Lower images surface topographic relief detected on $2 \mathrm{~cm}$ wide cables, sandbags, and laminated paper GCP targets

processing of this photo suite generated an ultradense point cloud $\left(26,560\right.$ points $\left./ \mathrm{m}^{2}\right)$ and a $6.1-\mathrm{mm}$ grid size DEM. Data of this resolution permits discretion of very subtle features, including footprints, cables, laminated sheets of paper, tire tracks, and surface fractures of $1 \mathrm{~cm}$ relief (Fig. 8).

\section{Discussion}

Four composite orthoimages were produced for the field area-one each pre-experiment and postexperiment, for both the test table grid and the nearfield grid. These orthoimages serve as a fully archival 

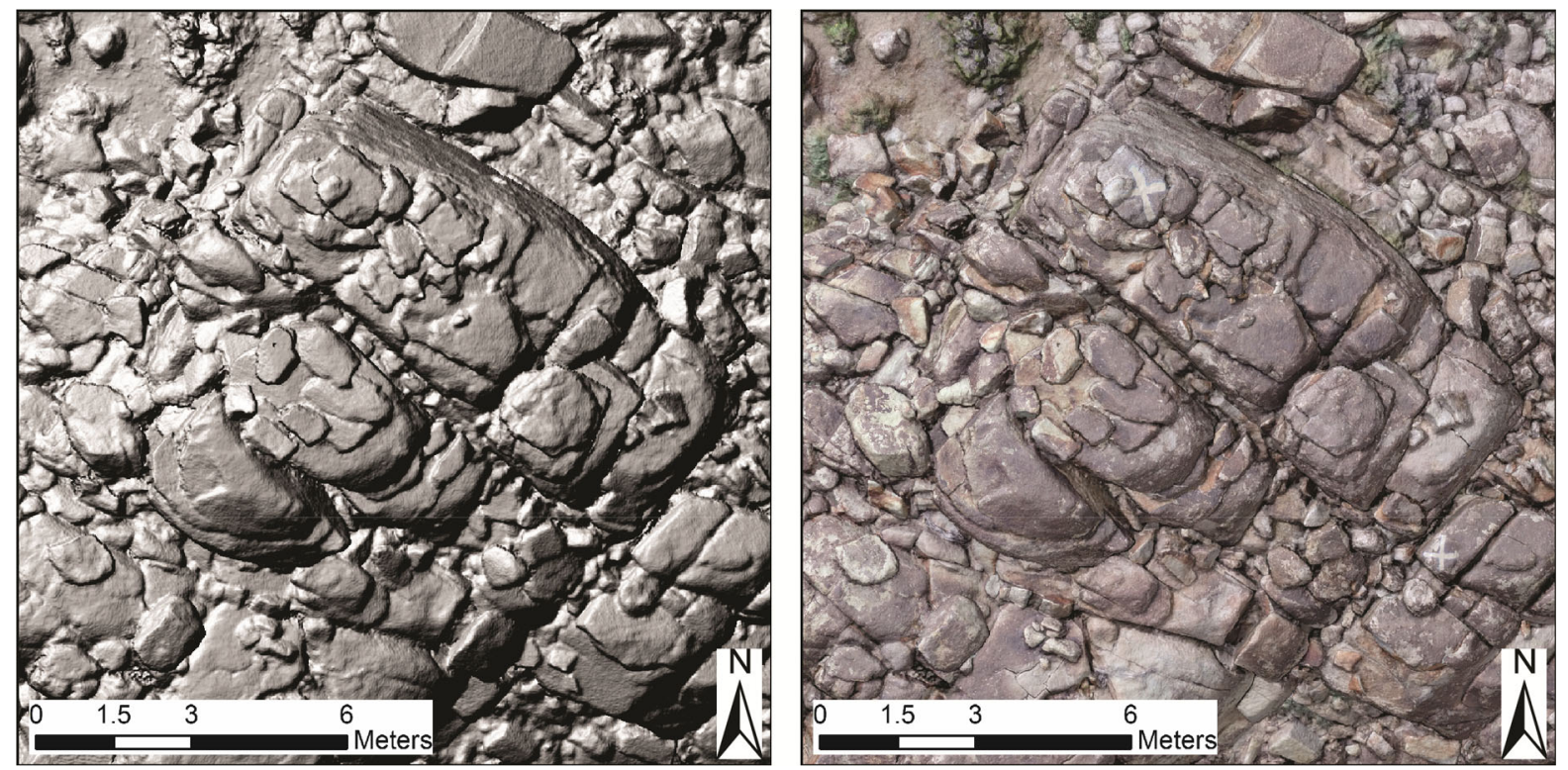

Figure 9

Hillshade map of the $7 \mathrm{~m}$-quartz monzonite outcrop west of the test table derived from $1.7 \mathrm{~cm}$ DEM from the near-field grid region. The right panel includes an orthoimage draped over the DEM with 50\% transparency. Individual cobbles and boulders, fractures, and GCP points (white crosses) are readily observable

dataset of the visible conditions of the field area before and after SPE-5. Figure 11 shows pre- and post-experiment comparative imagery within $5 \mathrm{~m}$ of the emplacement hole.

Within the post-experiment orthoimagery, surface fractures near surface ground zero are visible in a variety of orientations, with the greatest quantity of visible fractures appearing to be within $8 \mathrm{~m}$ of the emplacement hole. Also visible are regions of color change on the ground surface not present in the pretest orthoimagery. These discolored regions are surface deposits caused by geysering of perched groundwater via two instrumentation boreholes on the test table, as well as the evacuation of grout and gravel stemming material from the emplacement hole in the minutes following SPE-5 zero-time (Fig. 11).

This study compared DEMs, not point clouds, to assess site changes resulting from the underground experiment. The $\Delta z$ DEMs show that up to $18 \mathrm{~cm}$ uplift was recorded within a 2-m radius of surface ground zero (Figs. 12, 13a). Within $5 \mathrm{~m}$ of surface ground zero, a maximum of $7 \mathrm{~cm}$ of uplift was detected. The addition of material to the ground surface as a result of the evacuation of stemming material from the emplacement hole is visible (Fig. 12). Experiment-induced uplift of at least $2 \mathrm{~cm}$ is present over $70 \%$ of the graded test table. At the northern and southwesternmost corners of the graded test table, up to $2 \mathrm{~cm}$ of subsidence was recorded over a broad region. The steep margins of the muck pit exhibited raveling and erosion in certain locations, and redeposition of that material in downslope locations (Fig. 12).

The surfaces changes presented in this study can be compared to those measured by ground-based lidar for earlier experiments SPE-2 and SPE-3 (see Fig. 3). These experiments were shallower and smaller, but had the same scaled depth of burial, and thus would be expected to have broadly similar surface uplifts, at least within the same order of magnitude. The lidar-derived surface uplifts showed a maximum of $3 \mathrm{~cm}$ uplift on the graded test table, with contours showing elongation in a northeastsouthwest orientation (Fig. 3). Outside the gravelcovered area within $2 \mathrm{~m}$ of the shot, the photogrammetry-derived surface uplifts after SPE-5 show a maximum of $4 \mathrm{~cm}$ of uplift, with contours also elongated in a northeast-southwest direction 


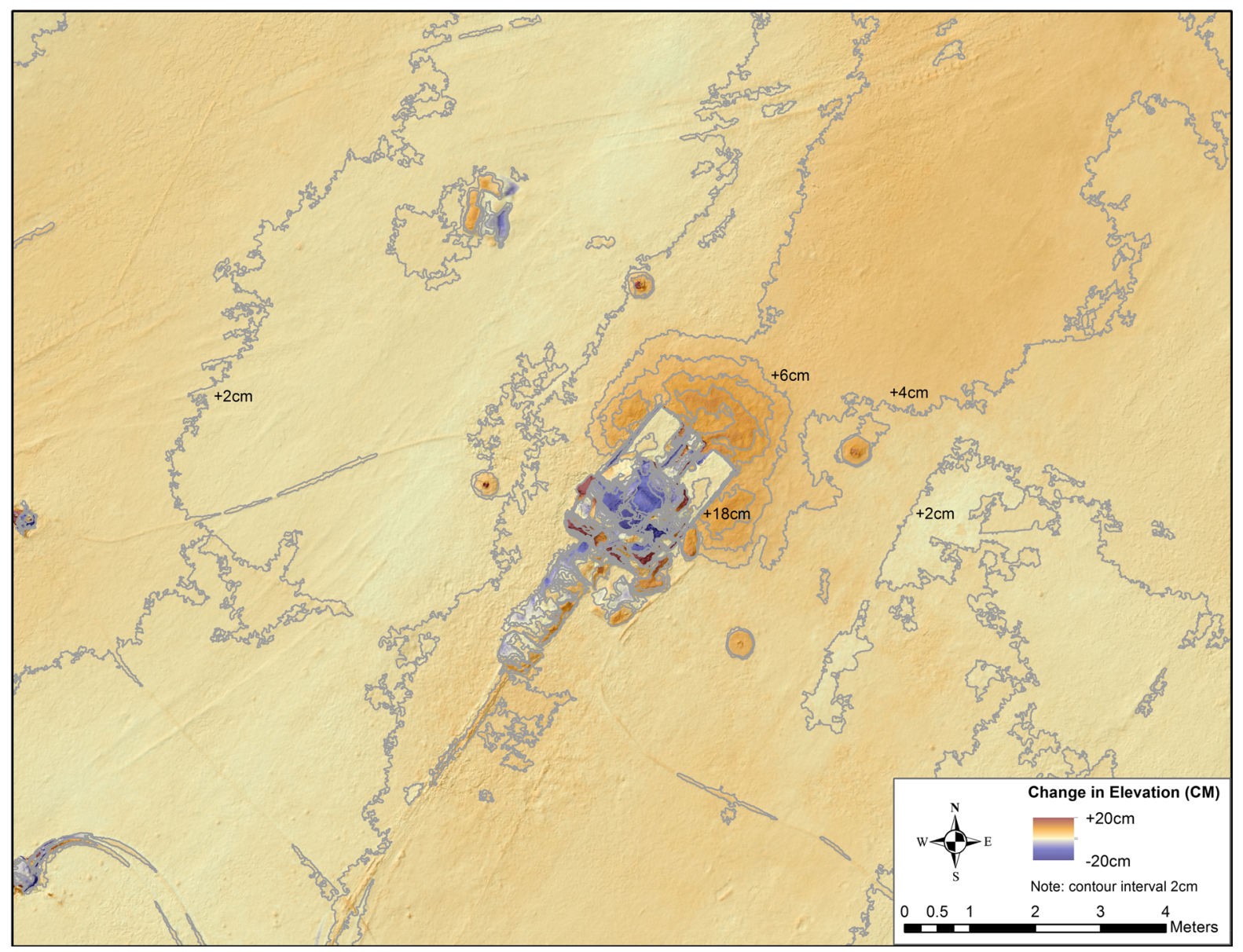

Figure 10

Contour map showing $\Delta z$ near-surface ground zero in the test table grid region

(Fig. 10). The similarity in magnitude and orientation of uplift from two different techniques provides confidence in these trends. Aligning broadly with the orientation of the Boundary Fault and with a major joint set identified by Orkild et al. (1983), our data suggest that the surface damage manifested from SPE-5 exploits a pre-existing structural grain in the Climax Stock host rock. Additional evidence is seen in the measured horizontal translation of GCPs following SPE-5 (Fig. 13b), which shows that 31 of 88 GCPs surveyed post-experiment record as much as $2.64 \mathrm{~cm}$ of lateral translation from their pre-experiment locations. Of those 31 GCPs with $\Delta x$ and/or $\Delta y, 29$ represent motion away from surface ground zero, and over half express vectors of motion towards the east and south.
Compared to the $2.8-\mathrm{cm}$ resolution terrestrial lidar data presented in Fig. 3 (Sussman et al. 2012; Schultz-Fellenz et al. 2013), the flexible and versatile UAS surface change characterization process provides DEM data of sub-centimeter resolution and captured data without requiring personnel to access the site and potentially destroy signatures. In addition to drastically increasing time efficiency in the field, the UAS photogrammetry method also permitted greater efficiency in computational processing time. Whereas the generation of DEMs from terrestrial lidar in prior SPE campaigns had taken weeks (due largely to the meshing of multiple scan setups), generation of DEMs from photogrammetric data took a matter of hours. The UAS method also offers more complete coverage of the study area. The image 

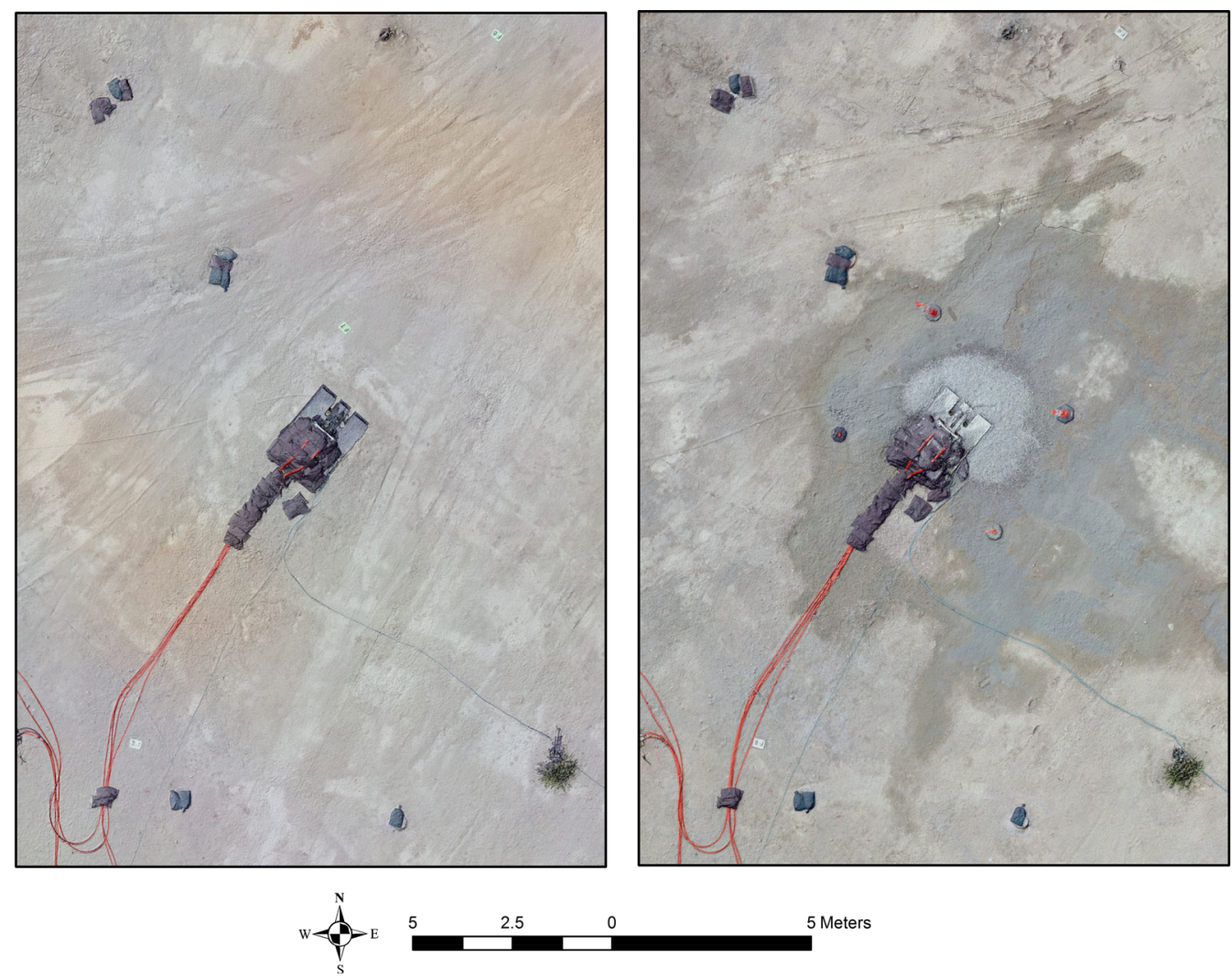

Figure 11

Orthophotos from surface ground zero in the test table grid region. Left panel from the pre-test dataset, right panel from the post test dataset. The region of darker material on the ground surface was a result of stemming material evacuation from the emplacement hole. A small fan of lighter-colored gravel is visible immediately adjacent to the northeast side of the emplacement hole

capture density and multiple flight passes over features during different times of day and varying sun angles minimized data gaps in shadowed regions.

UAS photogrammetry provides a direct technique to quantify surface spall of underground explosions at fine-scale resolution. The data resolution acquired in this investigation is critical for constraining collection requirements in applying this technology to monitoring and verification of underground explosions. This investigation shows that UAS-borne photogrammetry has the potential to further explore rapidly detected anomalous seismic signals in challenging terrain with centimeter- to sub-centimeter scale resolution.

Spallation results as the tensile stresses of the downgoing shock wave reflect off the free (ground) surface. Spall, a visible and measurable signature of geomaterial damage, is both a record of surface damage and a cue to additional damage in the subsurface (Patton et al. 2005, 2012; Sussman et al. 2016). The subsurface environment (i.e., material and fracture properties) imparts subtle yet significant impacts on the propagation, speed, and potential phase shifts of seismic waves resulting from the underground explosion (cf. Patton et al. 2012). Furthermore, quantification of surface spall, including total mass and spatial extent, can clarify fundamental modes of seismic surface waves and, therefore, improve confidence in moment tensor results from explosively induced seismic events (Patton 1991).

\section{Conclusions}

The use of low-altitude UAS-borne photogrammetry, along with a careful ground control point grid, 


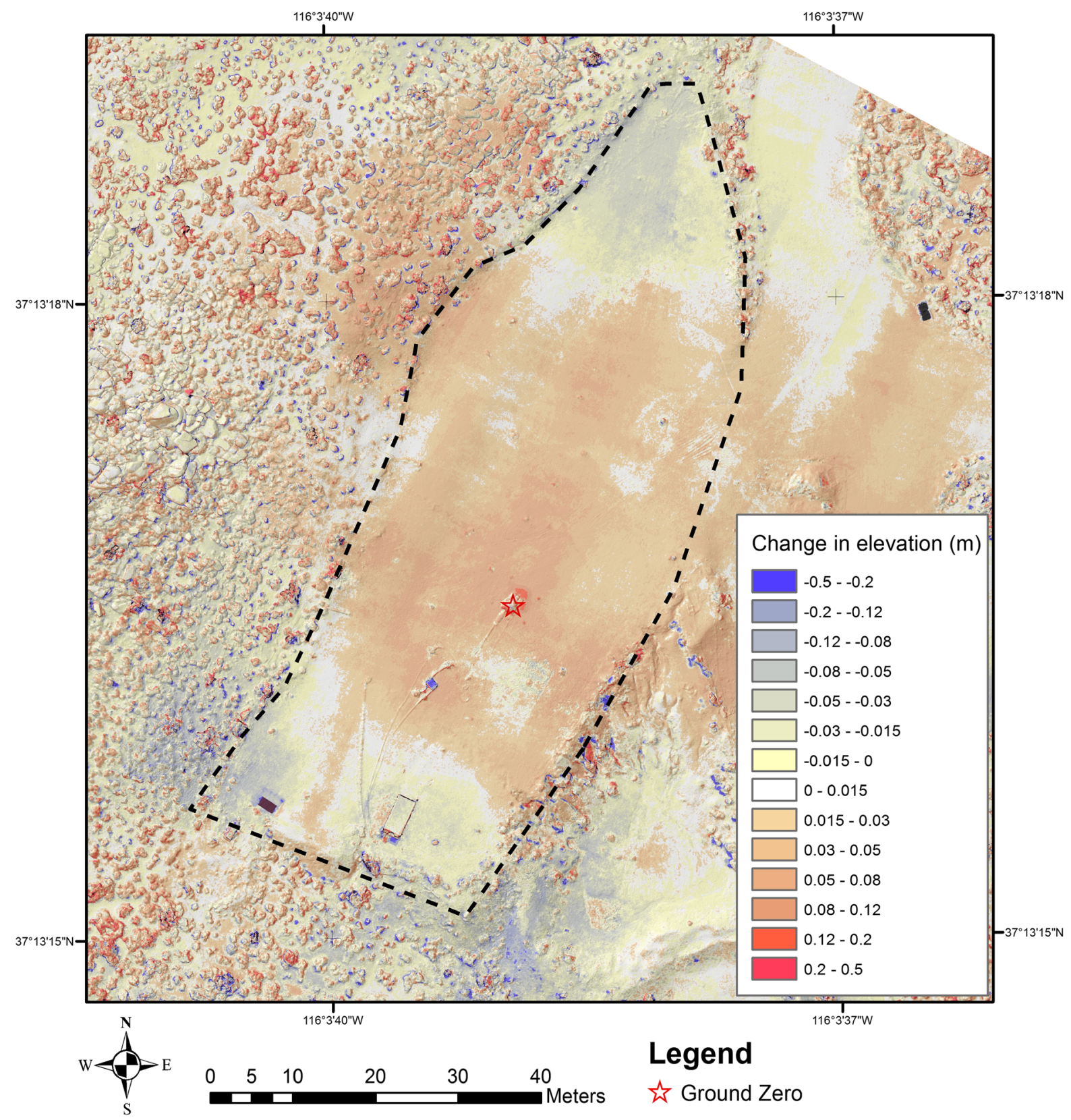

Figure 12

Surface $\Delta z$ across the test table grid region

produced DEMs with as dense as $6.1 \mathrm{~mm}$ grid size with little to no systemic error. The resolution of these datasets is sufficient to perform DEM difference calculations to detail discrete regions of uplift, subsidence, surface fractures, erosion, and deposition related to a controlled underground chemical explosion in granite. The rapid data collection occurred over less than eight flight hours per collection and fully covered the survey area. The method of collection ensured precision survey control on data while preserving subtle features.

Comparisons to terrestrial lidar over a section of the same region from previous tests in the SPE series show that while both techniques demonstrated the 

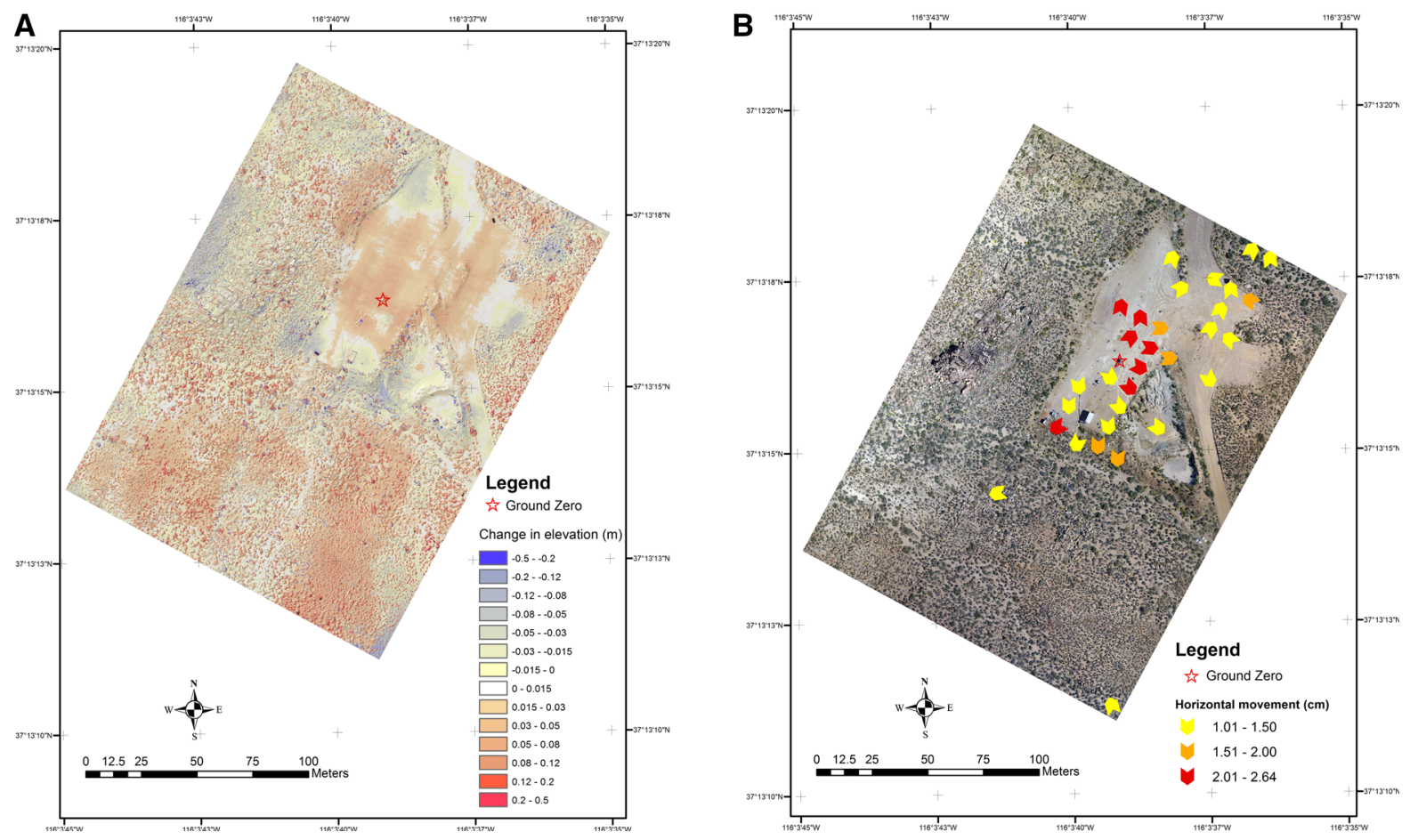

Figure 13

a Surface $\Delta z$ across the near-field grid region. b Horizontal translation ( $\Delta x$ and/or $\Delta y)$ as detected by repeat survey of GCPs. Color of arrow indicates range of movement; arrow vector points in direction of movement

capability to detect surface changes from the underground explosion, the UAS-based technique was faster, offered superior data resolution, had fewer coverage gaps, provided a less-invasive collection methodology, and acquired orthoimagery in addition to elevation information.

UAS photogrammetry can evaluate surface topographic changes created from small-yield underground explosions and has amplified impact when conducted in a manner that permits control from pre- and post-test conditions. The measured vertical surface topographic change resulting from the small-yield underground explosion carried out for the SPE-5 shot was on the order of $1-5 \mathrm{~cm}$ and locally as much as several tens of $\mathrm{cm}$. The maximum amount of topographic change was concentrated at the ground surface at, and immediately north of, the emplacement hole. When used both before and after execution of underground chemical explosions, this technique can be used to determine the baseline topography and quantify the explosion-induced changes to the surface. Our work suggests that the geologic environment plays a significant role in how, how much, and where the surface responds to underground explosions.

\section{Acknowledgements}

The Source Physics Experiments (SPE) would not have been possible without the support of many people from several organizations. The authors thank NNSA, the Office of Defense Nuclear Nonproliferation Research and Development, and the SPE working group, a multi-institutional, interdisciplinary group of scientists and engineers. This work relied on the skill, dedication, and focus of our UAS pilot, Michael Grimler of Los Alamos National Laboratory's Security Division, for safe and successful airborne operations. Katherine Norskog and Steven Clement of Los Alamos National Laboratory, Leon Berzins and Beth Dzenitis of Lawrence Livermore National Laboratory, TJ Williams of Sandia National Laboratories, and Jesse Bonner and Robert Ziehm of 
National Security Technologies, LLC provided essential field and logistics support. Los Alamos National Laboratory performs work for the US Department of Energy under contract DE-AC52-06NA25396. This document is unclassified and has been approved for unlimited release (LA-UR-16-29246).

Open Access This article is distributed under the terms of the Creative Commons Attribution 4.0 International License (http:// creativecommons.org/licenses/by/4.0/), which permits unrestricted use, distribution, and reproduction in any medium, provided you give appropriate credit to the original author(s) and the source, provide a link to the Creative Commons license, and indicate if changes were made.

\section{REFERENCES}

Bemis, S. P., Mickelthwaite, S., Turner, D., James, M. R., Akciz, S., Thiele, S. T., et al. (2014). Ground-based and UAV-based photogrammetry: a multi-scale, high-resolution mapping tool for structural geology and paleoseismology. Journal of Structural Geology, 69, 163-178.

Carbonneau, P. E., \& Dietrich, J. T. (2016). Cost-effective nonmetric photogrammetry from consumer-grade sUAS: implications for direct georeferencing of structure from motion photogrammetry. Proceedings of Landforms and Earth Surfaces. doi:10.1002/esp.4012.

Carrivick, J. L., Smith, M. W., \& Quincy, D. J. (2016). Structure from motion in the geosciences. New York: Wiley Blackwell.

Cattermole, J. M., \& Hansen, W. R. (1962). Geologic effects of the high-explosive tests in the USGS tunnel area, Nevada Test Site, US Geological Survey Professional Paper 382-B.

Fonstad, M. A., Dietrich, J. T., Courville, B. C., Jensen, J. L., \& Carbonneau, P. E. (2013). Topographic structure from motion: a new development in photogrammetric measurement. Earth Surface Processes and Landforms, 38, 421-430.

Garcia, M. N. (1997). Field and photogrammetric methods for mapping nuclear induced surface effects at the Nevada Test Site, Nye County. Nevada: US Geological Survey Open-File Report 97-695.

Glenn, N. F., Streuker, D. R., Chadwick, D. J., Thackray, G. D., \& Dorsch, S. J. (2006). Analysis of LiDAR-derived topographic information for characterizing and differentiating landslide morphology and activity. Geomorphology, 73, 131-148.

Grasso, D. N. (2001). GIS surface effects archive of underground nuclear detonations conducted at Yucca Flat and Pahute Mesa, Nevada Test Site, Nevada, US Geological Survey Open-File Report 01-272.

Gutierrez, R., Gibeaut, J. C., Smyth, R. C., Hepner, T. L., Andrews, J. R., Weed, C., Guteliuz, W., \& Mastin, M. (2001). Precise airborne lidar surveying for coastal research and geohazards applications. In Internationall Archives of Photogrammetry and Remote Sensing (Vol. XXXIV-3/W4), Annapolis.

X. Cong, Gutjahr, K. H., Schlittenhardt, J., \& Soergel, U. (2007). Measurement of surface displacement caused by underground nuclear explosions by differential SAR interferometry. In
International Society of Photogrammetry and Remote Sensing (Vol. XXXVI-1/W51), Hannover.

Houser, F. N., \& Poole, F. G. (1960). Age relations of the Climax composite stock, Nevada Test Site, Nye County, Nevada; USGS Misc. Investigations Map I-328, scale 1:4800.

Hugenholtz, C. H., Whitehead, K., Brown, O. W., Barchyn, T. E., Moorman, B. J., Le Clair, A., et al. (2013). Geomorphological mapping with a small unmanned aircraft system (sUAS): feature detection and accuracy assessment of a photogrammetricallyderived digital terrain model. Geomorphology, 194, 16-24.

James, M. R., \& Robson, S. (2012). Straightforward reconstruction of 3D surfaces and topography with a camera: accuracy and geoscience application. Journal of Geophysical Research, 117, F03017. doi:10.1029/2011JF002289.

James, M. R., \& Robson, S. (2014). Mitigating systematic error in topographic models derived from UAV and ground-based image networks. Earth Surf Processes and Landforms, 39, 1413-1420.

James, M. R., \& Varley, N. (2012). Identification of structural controls in an active lava dome with high-resolution DEMs: Volcan de Colima, Mexico. Geophysical Research Letters, 39, L22303. doi:10.1029/2012GL054245.

Johnson, K., Nissen, E., Saripalli, S., Arrowsmith, J. R., McGarey, P., Scharer, K., et al. (2014). Rapid mapping of ultrafine fault topography with structure from motion. Geosphere, 10(5), 18.

Jozkow, G., \& Toth, C. (2014). Georeferencing experiments with UAS imagery. ISPRS Annals of the Photogrammetry, Remote Sensing, and Spatial Information Sciences, II-1, 25-29. doi:10. 5194/isprsannals-II-1-25-2014.

Larmat, C., Rougier, E., \& Patton, H. (2017). Apparent explosion moments from $\mathrm{Rg}$ waves recorded on SPE. Bulletin of the Seismological Society of America, 107, 43-50.

Larmat, C. S., Steedman, D. W., Rougier, E, Delorey, A., \& Bradley, C. R. (2015). Coupling hydrodynamic and wave propagation modeling for waveform modeling of SPE. In EOS Trans $A G U$, abstract\#S53B-2799, 2015 AGU Fall Meeting, San Francisco.

Leprince, S., Berthier, E., Ayoub, F., Delacourt, C., \& Avouac, J.P. (2008). Monitoring Earth system dynamics with optical imagery. EOS, 89, 1-2.

Maldonado, F. (1977). Summary of the geology and physical properties of the Climax stock, Nevada Test Site: USGS Open File Report 77-356.

Micheletti, N., Chandler, J. H., \& Lane, S. N. (2015). Investigation the geomorphological potential of freely available and accessible structure-from-motion photogrammetry using a smartphone. Earth Surface Processes and Landforms, 40, 473-486.

Molinari, M., Medda, S., \& Villani, S. (2014). Vertical measurements in oblique aerial imagery. ISPRS International Journal of Geo-Information, 3, 914-928.

Niethammer, U., Rothmund, S., James, M. R., Travelletti, J., \& Joswig, M. (2010). UAV-based remote sensing of landslides. International Archives of Photogrammetry, Remote Sensing, and Spatial Information Sciences, XXXVIII(Part 5), 496-501.

Nouwakpo, S. K., Weltz, M. A., \& McGwire, K. (2015). Assessing the performance of structure-from-motion photogrammetry and terrestrial LiDAR for reconstructing soil surface microtopography of naturally vegetated plots. Earth Surface Processes and Landforms, 41, 308-322. doi:10.1002/esp.3787.

Orkild, P. P., Townsend, D. R., \& Baldwin, M. J. (1983) Chapter A; Geologic investigations. In Geologic and Geophysical 
Investigations of Climax Stock Intrusive, Nevada, USGS Open File Report 83-377.

Patton, H. J. (1991) Seismic moment estimation and the scaling of the long-period explosion source spectrum. In S. R. Taylor, H. J. Patton \& P. G. (Eds.) Richards explosion source phenomenology. American Geophysical Union, Washington, D.C. doi:10.1029/GM065p0171.

Patton, H. J. (2015). New insights into the explosion source from SPE. In EOS Trans. AGU, abstract S51F-05, 2015 AGU Fall Meeting, San Francisco.

Patton, H. J., Bonner, J. L., \& Gupta, I. N. (2005). Rg excitation by underground explosions: insights from source modeling the 1997 Kazakhstan depth-of-burial experiment. Geophysical Journal International, 163, 1006-1024.

Patton, H. J., Larmat, C., Rougier, E., Rowe, C. A., \& Yang, X. (2012). Seismic studies of Source Physics Experiments conducted at the Nevada National Security Site using close-in $(<2 \mathrm{~km})$ waveforms, 2012 Monitoring Research Review. Albuquerque: Ground-based Nuclear Explosion Monitoring Technologies.

Pelletier, J. D., \& Orem, C. A. (2014). How do sediment yields from post-wildfire debris-laden flows depend on terrain slope, soil burn severity class, and drainage basin area? Insights from airborne-LiDAR change detection. Earth Surface Processes and Landforms, 39, 1822-1832.

Phang, M. K., Simpson, T. A., \& Brown, R. C. (1983) Investigation of blast-induced underground vibrations from surface mining, US Department of Interior Office of Surface Mining Report.

Piras, M., Taddia, G., Forno, M. G., Gattaglio, M., Aicardi, I., Dabove, P., et al. (2017). Detailed geologic mapping in mountain areas using an unmanned aerial vehicle: application to the Rodoretto Valley, NW Italian Alps. Geomatics, Natural Hazards and Risks, 8, 137-149.

Reshetyuk, Y., \& Martensson, S.-G. (2016). Generation of highly accurate digital elevation models with unmanned aerial vehicles. The Photogrammetric Record, 31, 143-165. doi:10.1111/phor.12143.

Scaioni, M., Longoni, L., Mellilo, V., \& Papini, V. (2014). Remote sensing for landslide investigations: an overview of recent achievements and perspectives. Remote Sensing, 6, 1-53.
Schultz-Fellenz, ES, AJ Sussman, RE Kelley, and DI Cooper, 2013, Post-shot surface damage detected with lidar at the Source Physics Experiment Site. In EOS Trans. AGU, abstract S31E-04, 2013 AGU Fall Meeting, San Francisco.

Snelson, C. M., Abbott, R. E., Broome, S. T., Mellors, R. J., Patton, H. J., Sussman, A. J., et al. (2013). Chemical explosion experiments to improve nuclear test monitoring. Eos, 94, 237-239.

Sussman, A. J., Schultz-Fellenz, E. S., Broome, S. T., Townsend, M. J., Abbott, R. E., Snelson, C. M., Cogbill, A., Conklin, G., Mitra, G., \& Sabbeth, L. (2012). Characterization of the source physics experiment site. In EOS Trans. AGU, abstract S21C-03, 2012 AGU Fall Meeting, San Francisco.

Sussman, A. J., Swanson, E., Wilson, J., Townsend, M., \& Prothro, L. (2016). Multi-scale fracture damage associated with underground chemical explosions. In EOS Trans. AGU, abstract MR41A-2686, 2016 AGU Fall Meeting, San Francisco.

Tuffen, H., James, M. R., Castro, J. M., \& Schipper, C. I. (2013). Exceptional mobility of an advancing rhyolitic obsidian flow at Cordon Caulle volcano in Chile. Nature Communications. doi:10.1038/ncomms3709.

Warrick, J. A., Ritchie, A. C., Adelman, G., Adelman, K., \& Limber, P. W. (2016). New techniquest to measure cliff change from historical oblique aerial photographs and structure-frommotion photogrammetry. Coastal Research, 33, 39-55.

Westoby, M. J., Brasington, J., Glasser, N. F., Hambrey, M. J., \& Reynolds, J. M. (2012). 'Structure from Motion' photogrammetry: a low-cost, effective tool for geoscience applications. Geomorphology, 179, 300-314.

A. H. Chowdhury, \& Wilt, T. E. (2015). Characterizing explosive effects on underground structures, US Nuclear Regulatory Commission report NUREG/CR-7201.

Yu, H., Yuan, Y., Yu, G., \& Liu, X. (2014). Evaluation of influence of vibrations generated by blasting construction on an existing tunnel in soft soil. Tunneling and Underground Space Technology, 43, 59-66. 